\title{
Design and reliability analysis of accommodation work barge mooring configuration at a tension leg platform in Makassar Strait, Indonesia
}

\author{
Antonio Juan ${ }^{1, *}$, Paramashanti ${ }^{2}$, Rildova $^{2}$, and Heri Setyawan ${ }^{2}$ \\ ${ }^{1}$ Ocean Engineering Study Program, Faculty of Civil and Environmental Engineering, Institut Teknologi Bandung, Bandung, Indonesia \\ ${ }^{2}$ Offshore Engineering Research Group, Faculty of Civil and Environmental Engineering, Institut Teknologi Bandung, Bandung, \\ Indonesia
}

\begin{abstract}
An Accommodation Work Barge in Makassar Strait attaches to a Tension Leg Platform (TLP), a floating offshore platform operating in deep-water oil and gas field for a well intervention project. The mooring system are tied up to the north mooring lines of the vessel, whilst hawsers from the TLP connected to the south lines of the vessel. The TLP is fitted with two "TH" lines on its south side. However, these "TH" lines fail due to the unknown reason. The purpose of this study is to evaluate mooring performances to support the TLP operation by using API RP2SK recommendation, which suggests line tension limit, TLP offset, and minimum clearance between facilities. This study assesses reliability index $(\beta)$ of the recommended design to evaluate whether the TH lines are required or could be eliminated. Mooring analysis is performed using ORCAFLEX for intact and damaged condition, while Monte Carlo simulation is performed to get system failure probability with minimum breaking strength ratio (\%MBS) as required parameter. From the results, it is found that TH lines could be eliminated, as they do not affect significantly to the system. The analysis delivers a very secure index $(\beta=14.676)$ with probability of failure below $10-5$.
\end{abstract}

\section{Introduction}

The purpose of this paper is to verify the mooring performances of the vessel connected to the TLP in Makassar Strait, Indonesia and the impact of the mooring forces on the TLP offset performances. More precisely to evaluate required mooring pattern, configuration, and properties, provide separation distance to ensure safe clearance between facilities, and provide recommendation as to whether $\mathrm{TH}$ mooring legs are required or could be eliminated. This study also provide basis for required mooring accessories to be prepared.

One criteria in designing a floating offshore structure is about its mooring system [1,2]. A Tension Leg Platform (TLP) as one of the floating offshore oil and gas platform is suit to operate in deep water $(1000 \mathrm{~m}-1500 \mathrm{~m})$. Once in its lifetime, a well intervention usually needed to make an improvement to the well. This long process needs extra facilities to support accommodation.

An Accommodation Work Barge (AWB) is working at TLP in Makassar Strait, Indonesia for a well intervention project. The system installed with 4 mooring lines D1 to D4 which tied up to the north of the vessel, whilst 4 hawser lines connect TLP to the south lines of the vessel and is fitted with 2 lines TH1 and TH2 on the south side. However, the $\mathrm{TH}$ lines are having a failure issue due to unknown reason. Therefore, a mooring analysis performed to evaluate required mooring pattern, properties to support this operation using American Petroleum Institute Design and Analysis of Station keeping Systems for Floating Structures (API RP2SK) recommendation. The criteria suggest the line tension limit, TLP offset, and minimum clearance between facilities. This API practices requires that the design load for floating platform is $100 \mathrm{yr}$, return period wave height combined with associated wind and current $[3,4]$.

To achieve those objectives, the mooring analysis will determine:

- Recommended mooring pattern and vessel position. Hawser configuration (length, diameter, breaking load)

- Require length of mooring line out of the fairlead

- Initial line tension

- Limiting environment for storm conditions (100-YRP)

- Results comparison of line tension, TLP offset, and clearance with and without $\mathrm{TH} 1$ and $\mathrm{TH} 2$ mooring lines to ensure that the system is within acceptable limit for both conditions.

In this paper, reliability analysis will provide reliability index $(\beta)$ of design recommendation whether $\mathrm{TH}$ mooring lines are required or could be eliminated. This analysis will cover the presence of uncertainty in its structural capacity and the environmental load that occur 
[5]. Therefore, we can assess the probability of failure in this system and know how secure the system is.

\section{Study Cases}

\subsection{Mooring analysis}

To evaluate the proposed mooring system of the AWB at the north face of the TLP, we have run a mooring analysis following the API RP 2 SK recommendations. The mooring analysis has been performed with the computer program ORCAFLEX from Orcina using a coupled model of the TLP and the AWB.

There are various loading mechanisms acting on a moored floating vessel [1]. For this study, the excitation forces caused by current are assumed temporarily constant, with spatial variation depending on the current profile and direction with depth. Wind loading is taken as constant, at least, in initial design calculations, though gusting can produce slowly varying responses. Wave forces result in time-varying vessel motions in the six rigid body degrees of freedom of surge, sway, heave, roll, pitch, and yaw [2]. This illustration as depicted in Fig. 1.

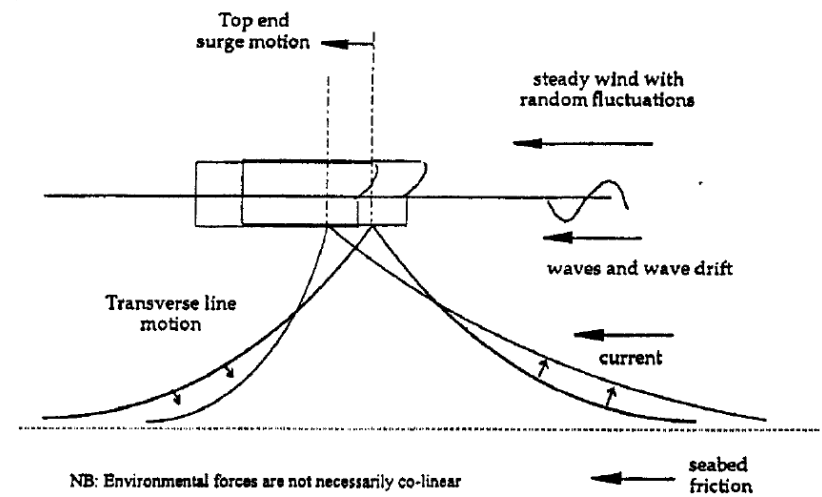

Fig. 1. Environmental forces on a moored vessel

The drag loads due to translational velocity of the sea and air past the vessel are calculated using the standard OCIMF method outlined below [6]. This method calculates the surge, sway, and yaw drag loads on a stationary vessel. ORCAFLEX extends this to a moving vessel by replacing the current (or wind) velocity used in the OCIMF method with the relative translational velocity of the current (or wind) past the vessel. More precisely, the relative velocity is that of the current (or wind), relative to the low frequency primary motion of the vessel, at the current (or wind) load origin. In other words, the relative velocity includes the current but not the waves, and it includes the low frequency primary motion of the vessel, but not the wave frequency motion or the superimposed motion.

The drag loads due to surge and sway relative velocity are calculated as given by the following OCIMF formulae.

Where:

$$
\begin{gathered}
f_{x}=\frac{1}{2} C_{\text {surge }} \cdot \rho|v|^{2} A_{\text {surge }} \\
f_{y}=\frac{1}{2} C_{\text {sway }} \cdot \rho|v|^{2} A_{\text {sway }} \\
m_{z}=\frac{1}{2} C_{\text {yaw }} \cdot \rho|v|^{2} A_{\text {yaw }}
\end{gathered}
$$

- $f_{x}, f_{y}$, and $m_{z}$ are the drag force in the $\mathrm{x}$ - and $\mathrm{y}$ directions and moment about $\mathrm{z}$ - direction

- $C_{\text {surge }}, C_{\text {sway }}$ and $C_{\text {yaw }}$ are the surge, sway and yaw drag coefficients for the current or wind direction relative to the low frequency vessel heading

- $\rho$ is the water density (for current) or air density (wind)

- $v$ is the relative velocity of the sea or air past the vessel

For the AWB, wind and current drag coefficients, were used from the vessel's data [7]. The drift forces and vessel motions were obtained by a hydrodynamic analysis using MOSES computer program.

For the TLP, wind and current drag coefficients also used from the TLP data. TLP hydrodynamic motions RAOs and Quadratic Transfer functions are generated by a hydrodynamic analysis using MOSES. The TLP actual mechanical properties (actual tendons and riser tensions) are given by TLP data. The tendons and risers' tensions are used to define the TLP motions and offsets, but it is not the intention of this paper to verify the tension in the riser and tendons.

\subsection{Reliability analysis}

To assess probability of failure of the recommended design, we performed reliability analysis using Monte Carlo Simulation [5]. This analysis is used to cover numerous sources of uncertainty in the load and resistance related parameters of a designed structure. (See Fig. 2 below).

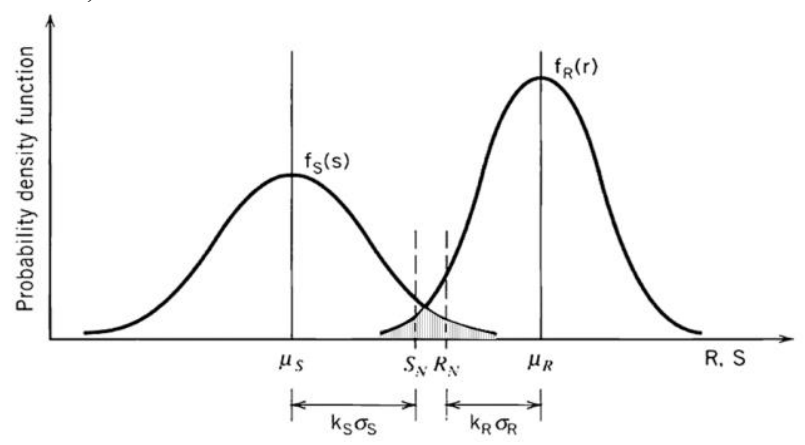

Fig. 2. Load and resistance distribution

Where the uncertainties in the load and resistance variables are expressed in the form of the probability density functions, we can express the measure of risk in terms of the probability of the failure event or $\mathrm{P}(\mathrm{R}<\mathrm{S})$ as this formula:

$$
\begin{aligned}
p_{f} & =P(\text { failure })=P(R<S) \\
& =\int_{0}^{\infty}\left[\int_{0}^{s} f_{R}(r) d r\right] f_{S}(s) d s \\
& =\int_{0}^{\infty} F_{R}(s) f_{S}(s) d s
\end{aligned}
$$

Where $F_{R}(s)$ is the Cumulative Distribution Function of $\mathrm{R}$ evaluated at $\mathrm{s}$. The probability of failure in terms of the safety index can be obtained as:

$$
p_{f}=\Phi(-\beta)=1-\Phi(\beta)
$$

Load parameter is constant, and the resistance parameter is based on line tension minimum breaking load (MBL). The event failure is when loads occur on the line are greater than its capacity. So, the performance function [5] is written as: 


$$
\mathrm{Z}=\mathrm{g}(R, S)=R-S
$$

We performed 50 simulations to assess distribution of the MBL percentage for each simulation.

\subsection{Methodology}

The step of this study is shown in flowchart Fig. 3 below.

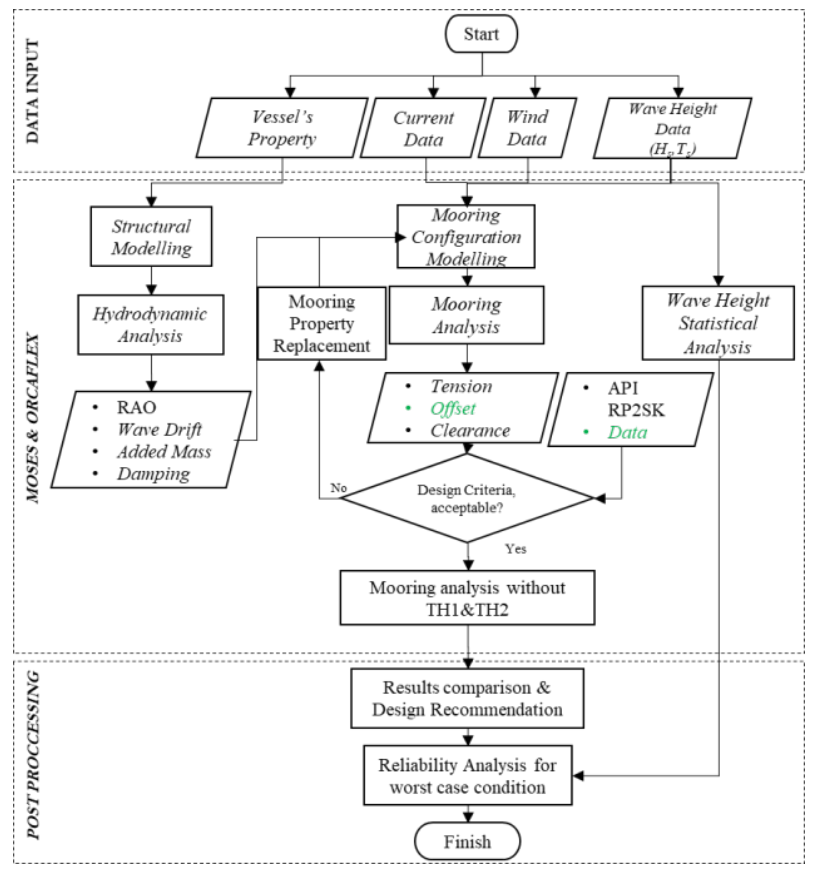

Fig. 3. Flowchart of the study

Mooring analysis performed for intact and damaged condition using API recommendation for dynamic analysis. For intact condition, dynamic analysis safety factor for tension limit is $60 \%$, and offset limit is 3\% water depth. For damage condition, it is $80 \% \mathrm{MBL}$ and $5 \%$ water depth. The horizontal clearance recommendation between facilities is $10 \mathrm{~m}$ for both operating and storm condition [3].

\section{Results and Discussion}

\subsection{Mooring analysis Results}

The simulations are performed for eight different environmental heading cases as shown in Table 1 [8].

Table 1. Environmental heading cases, 100YRP

\begin{tabular}{|c|c|c|c|c|c|c|c|c|c|c|}
\hline \multicolumn{2}{|c|}{100 - Year Return Storm } & $\mathrm{N}$ & $\mathrm{NE}$ & $\mathbf{E}$ & SE & $\mathbf{S}$ & SW & W & NW & Omni \\
\hline Significant Wave & & & & & & & & & & \\
\hline Height $(\mathrm{Hs})$ & (m) & 3.0 & 2.5 & 2.4 & 1.2 & 1.9 & 1.4 & 1.9 & 1.9 & 3.0 \\
\hline Peak Period (Tp) & (s) & 8.3 & 7.6 & 7.4 & 5.3 & 6.5 & 5.6 & 6.7 & 6.6 & 8.3 \\
\hline Hmax & (m) & 5.5 & 4.6 & 4.4 & 2.2 & 3.4 & 2.5 & 3.6 & 3.5 & 5.5 \\
\hline Thmax & (s) & 7.8 & 7.2 & 7.0 & 5.0 & 6.2 & 5.3 & 6.3 & 6.3 & 7.8 \\
\hline 1-hr wind speed & $(\mathrm{m} / \mathrm{s})$ & 21.2 & 18.7 & 18.0 & 11.7 & 15.5 & 12.7 & 15.9 & 15.7 & 21.2 \\
\hline Current Speed & $(\mathrm{m} / \mathrm{s})$ & 1.31 & 0.78 & 0.78 & 0.78 & 1.31 & 0.78 & 0.78 & 0.78 & 0.78 \\
\hline
\end{tabular}

For each dynamic analysed case, a time domain simulation is performed with 3 -hour duration each and a time step of 0.1-s [1]. The analysis using ORCAFLEX software is performed for the coupled model of TLP and AWB (see Fig.4).

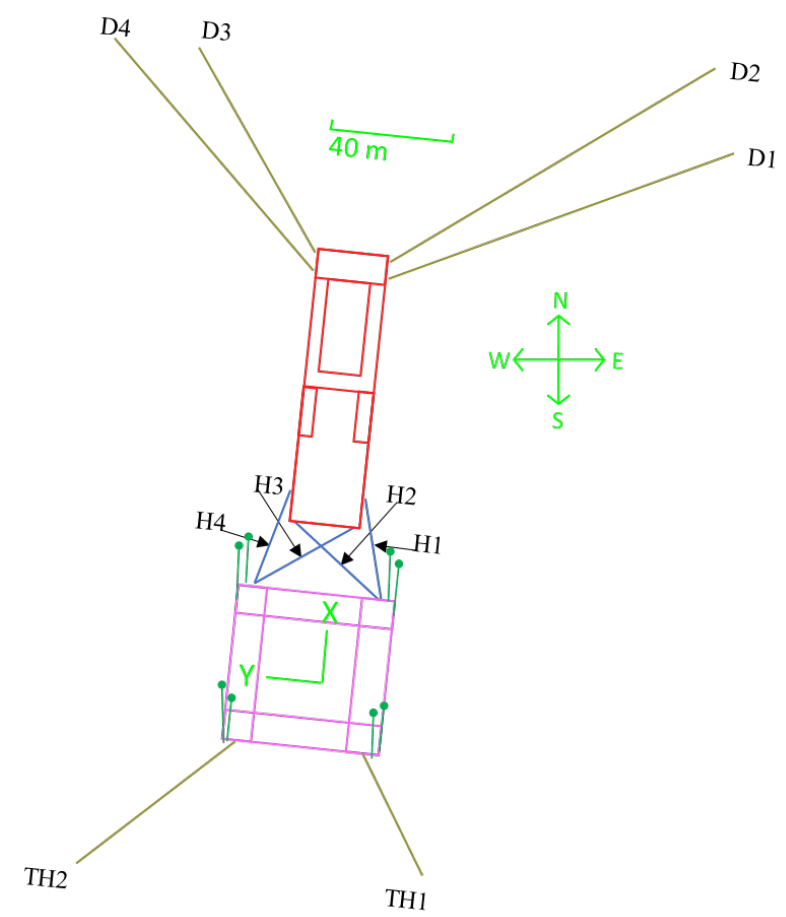

Fig. 4. Coupled model of TLP and AWB

The analysis results present the maximum tension in the vessel and TLP mooring lines, the vessel and TLP offset and motions as well as the clearance between the two vessels. The tendon and riser tensions are excluded.

The model has been validated by checking its stability and response frequency in regular waves.

From the analysis, it is recommended to change the AWB mooring lines connected to the TLP with new IWRC 54mm wires with MBL 174 tonnes from EEIPS 38 mm wires with MBL 90 tonnes [9].

After this replacement in the mooring properties to increase strength, we compared the results using dynamic analysis with and without TH1 \& TH2 lines for intact and damaged condition. The criteria which been compared is the maximum line tension, TLP offsets and clearance between two vessels.

\subsubsection{Line Tension}

Results comparison between line tension for each condition show in figures below. The vertical coordinate represents value of the line tension in tonnes and horizontal coordinate represent each environmental heading cases. Results for analysis where TH lines are included is connected by continuous lines and for condition where TH lines are excluded is connected with dotted lines.

For intact condition, the graph shows the line tension comparison for mooring lines connected to the north of vessel (D1 - D4) as shown in Fig.5, and for hawser lines (H1 - H4) which connect the vessel to the TLP as shown in Fig. 6 below. 


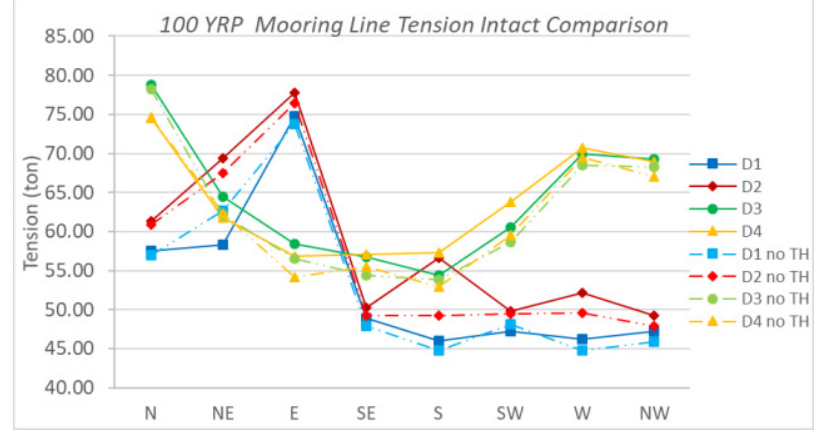

Fig. 5. D1 - D4 line tension comparison, intact condition

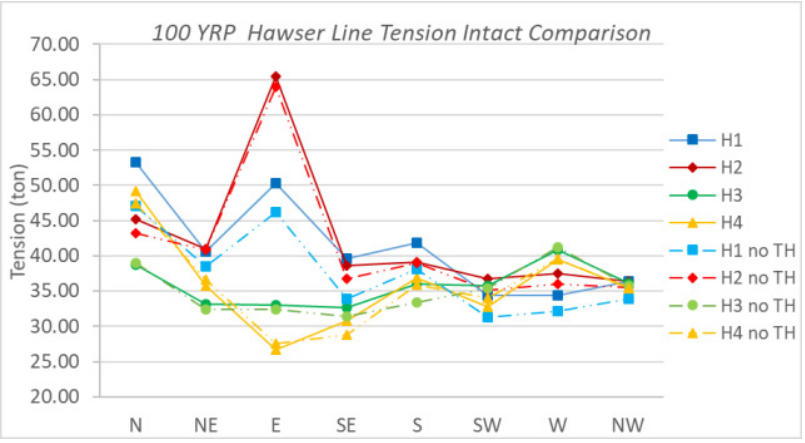

Fig. 6. H1 - H4 line tension comparison, intact condition

Whilst for damaged condition is shown in Fig.7 and Fig.8. For these graph, zero (0) value of the line tension means condition for the failed line which occur at different lines depends on each environmental heading case.

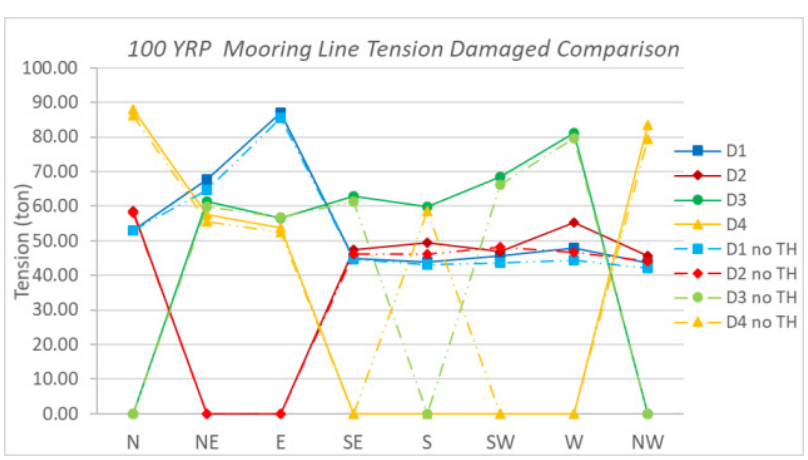

Fig. 7. D1 - D4 line tension comparison, Damaged condition

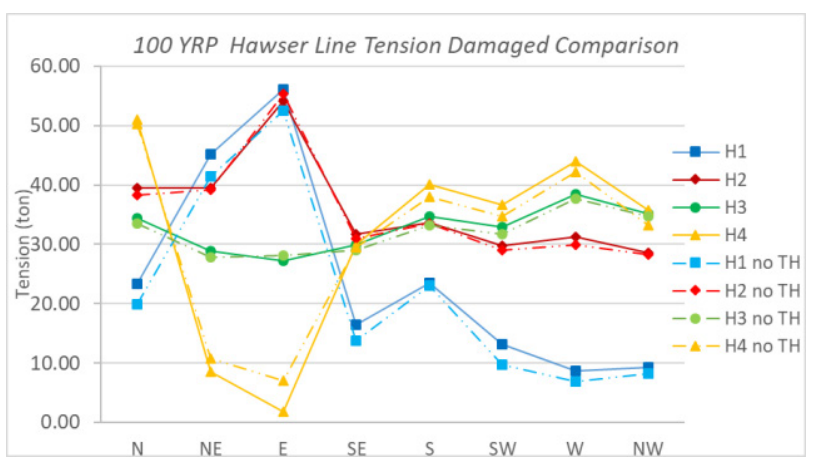

Fig. 8. H1 - H4 line tension comparison, Damaged condition

From the graphs above, we see that there is no significant effect to the line tension for intact or damaged condition, whether TH lines is included or excluded. Detailed results for both conditions shown in Table 2 below.

Table 2. Line tension results comparison, with and without TH1\&TH2

\begin{tabular}{|c|c|c|c|c|c|c|c|c|c|c|c|c|c|}
\hline \multicolumn{14}{|c|}{ Tension Results: 100 YRP } \\
\hline \multirow{2}{*}{\multicolumn{2}{|c|}{$\begin{array}{l}\text { Environment } \\
\text { Heading }\end{array}$}} & \multirow{2}{*}{\multicolumn{2}{|c|}{$\begin{array}{c}\text { Failed } \\
\text { Line } \\
\text { No } \\
\end{array}$}} & \multicolumn{6}{|c|}{ Fairlead } & \multicolumn{2}{|c|}{ FOS } & \multicolumn{2}{|c|}{ FOS } \\
\hline & & & & \multicolumn{2}{|c|}{$\begin{array}{l}\text { Line } \\
\text { No }\end{array}$} & \multicolumn{2}{|c|}{$\begin{array}{c}\operatorname{Max} \\
t\end{array}$} & \multicolumn{2}{|c|}{$\begin{array}{c}\text { Tension } \\
\text { \%MBS }\end{array}$} & Achieved & $\begin{array}{l}\text { riteria } \\
2 S K\end{array}$ & Achieved & $\begin{array}{r}\text { Criteria } \\
2 \mathrm{SK}\end{array}$ \\
\hline \multicolumn{2}{|l|}{ TH Line } & $\begin{array}{c}\text { With } \\
\text { TH }\end{array}$ & No TH & $\begin{array}{c}\text { With } \\
\text { TH }\end{array}$ & No TH & $\begin{array}{c}\text { With } \\
\text { TH }\end{array}$ & No TH & $\begin{array}{c}\text { With } \\
\text { TH }\end{array}$ & No TH & \multicolumn{2}{|c|}{ With TH } & \multicolumn{2}{|c|}{ No TH } \\
\hline \multirow[t]{2}{*}{ North } & intact & & & D3 & D3 & 78.8 & 78.2 & $45.3 \%$ & $44.9 \%$ & 2.21 & 1.67 & 2.22 & 2.00 \\
\hline & Damaged & D3 & D3 & D4 & D4 & 87.9 & 86.2 & $50.5 \%$ & $49.6 \%$ & 1.98 & 1.25 & 2.02 & 1.25 \\
\hline \multirow[t]{2}{*}{ North East } & intact & & & D2 & D2 & 69.4 & 67.5 & $39.9 \%$ & $38.8 \%$ & 2.51 & 1.67 & 2.58 & 2.00 \\
\hline & Damaged & D2 & D2 & D1 & D1 & 67.6 & 64.5 & $38.8 \%$ & $37.1 \%$ & 2.57 & 1.25 & 2.70 & \\
\hline \multirow[t]{2}{*}{ East } & intact & & & D2 & D2 & 77.8 & 76.4 & $44.7 \%$ & $43.9 \%$ & 2.24 & 1.67 & 2.28 & 2.00 \\
\hline & Damaged & D2 & D2 & D1 & D1 & 87.1 & 85.6 & $50.0 \%$ & $49.2 \%$ & 2.00 & 1.25 & 2.03 & 1.25 \\
\hline \multirow[t]{2}{*}{ South East } & intact & & & D4 & D4 & 57.1 & 55.6 & $32.8 \%$ & $31.9 \%$ & 3.05 & 1.67 & 3.13 & 2.00 \\
\hline & Damaged & D4 & D4 & D3 & D3 & 62.8 & 61.3 & $36.1 \%$ & $35.2 \%$ & 2.77 & 1.25 & 2.84 & 1.25 \\
\hline \multirow[t]{2}{*}{ South } & intact & & & D4 & D3 & 57.3 & 53.8 & $32.9 \%$ & $30.9 \%$ & 3.04 & 1.67 & 3.23 & 2.00 \\
\hline & Damaged & D4 & D3 & D3 & D3 & 59.8 & 58.5 & $34.3 \%$ & $33.6 \%$ & 2.91 & 1.25 & 2.97 & 1.25 \\
\hline \multirow[t]{2}{*}{ South West } & intact & & & D4 & D4 & 63.8 & 59.5 & $36.7 \%$ & $34.2 \%$ & 2.73 & 1.67 & 2.92 & 2.00 \\
\hline & Damaged & D4 & D4 & D3 & D3 & 68.6 & 66.1 & $39.4 \%$ & $38.0 \%$ & 2.54 & 1.25 & 2.63 & 1.25 \\
\hline \multirow[t]{2}{*}{ West } & intact & & & D4 & D4 & 70.7 & 69.5 & $40.6 \%$ & $40.0 \%$ & 2.46 & 1.67 & 2.50 & 2.00 \\
\hline & Damaged & D4 & D4 & D3 & D3 & 81.2 & 79.5 & $46.7 \%$ & $45.7 \%$ & 2.14 & 1.25 & 2.19 & 1.25 \\
\hline \multirow[t]{2}{*}{ North West } & intact & & & D3 & D3 & 69.3 & 68.2 & $39.8 \%$ & $39.2 \%$ & 2.51 & 1.67 & 2.55 & 2.00 \\
\hline & Damaged & D3 & D3 & D4 & D4 & 83.4 & 79.4 & $47.9 \%$ & $45.6 \%$ & 2.09 & 1.25 & 2.19 & 1.25 \\
\hline
\end{tabular}

The worst results as show in table 2 above, is the maximum line tension occurs at line D4 with $\mathbf{5 0 . 5 \%}$ MBS for damaged (1-line failure) condition.
This worst case occurs when the system takes an environmental force from north direction. All mooring lines tension safety factor are satisfied with the new lines. 


\subsubsection{TLP Offset and Clearance}

We compared the TLP offset performances due to impact of the mooring lines and the separation distance between vessel and TLP. The offset for intact and damaged condition as shown in Fig. 9 below.
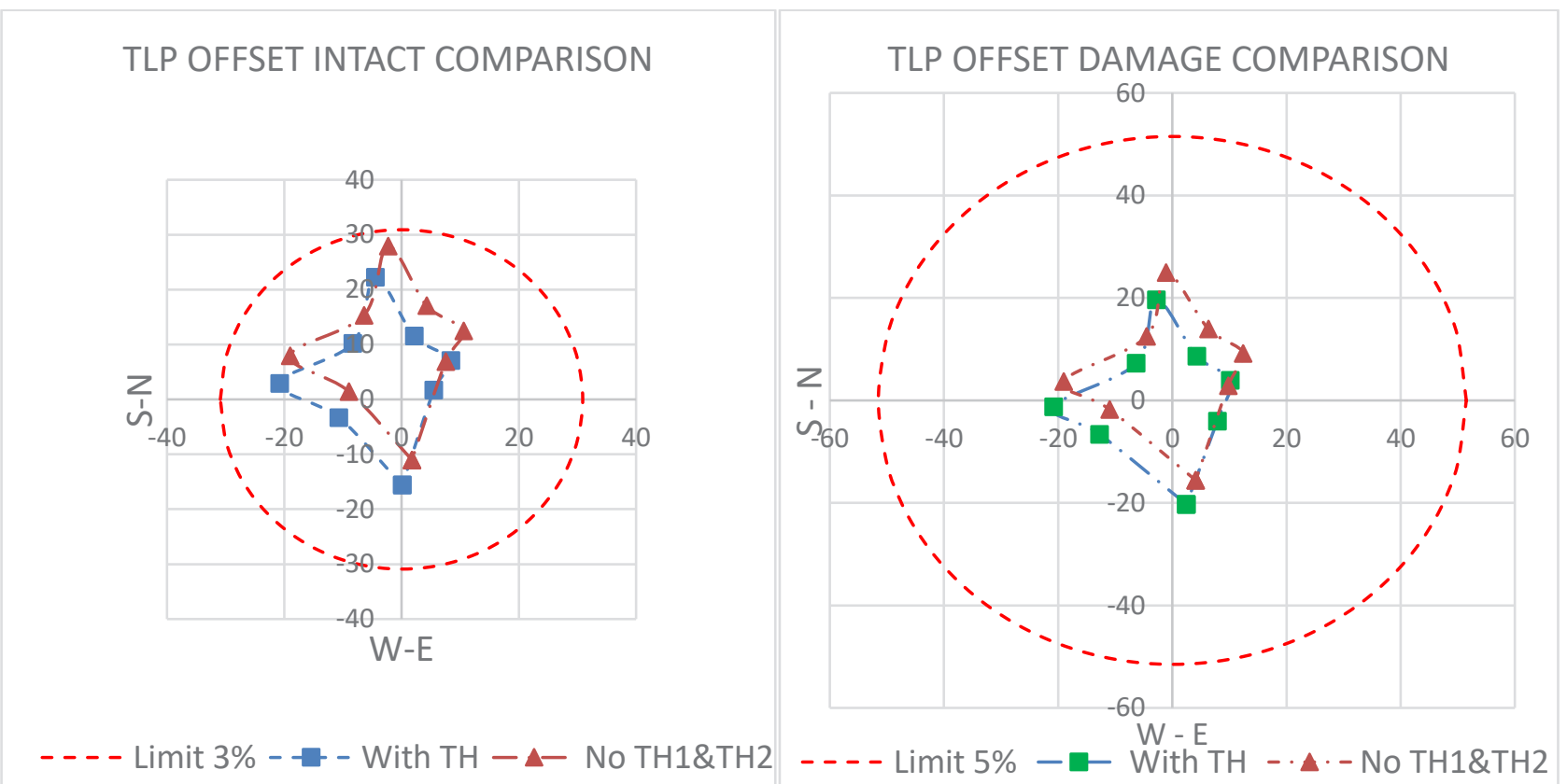

Fig. 9. TLP offsets comparison for Intact and Damaged condition

The maximum TLP offset occurs in the 100 YRP conditions from South, with and without TH lines where the offset reach $28 \mathrm{~m}$ to North. This number almost exceeding the acceptance criteria (3\% limit) $30 \mathrm{~m}$ for intact condition.
The minimum clearance comparison for both intact and damaged condition shown in Fig.10 below. The analysis asses the minimum separation distance between vessel surfaces during time simulation.

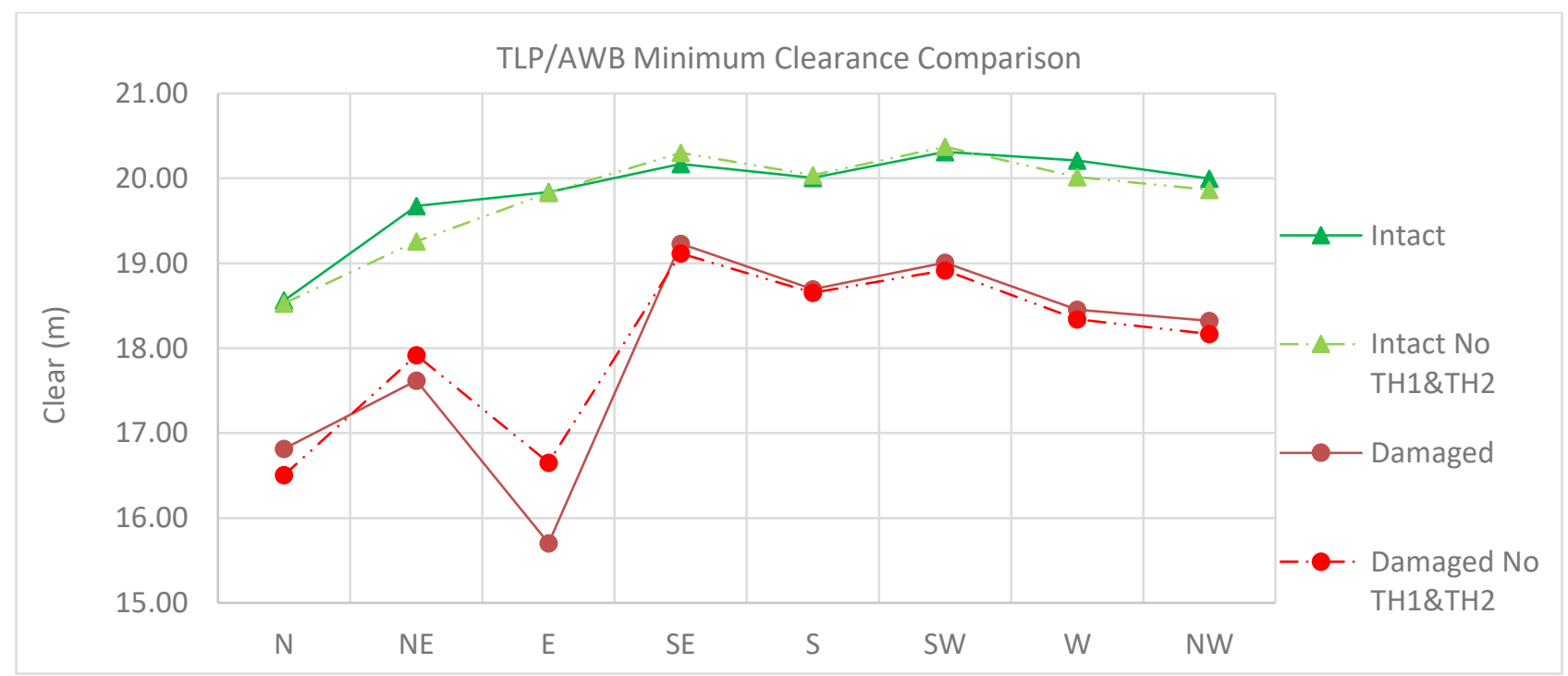

Fig. 10. AWB/TLP Clearance results comparison

Minimum clearance occurs when TH lines is included during damaged condition, the minimum separation distance recorded at $15.7 \mathrm{~m}$ when system took an environmental force coming from East direction. Although this result still satisfied the API acceptance criteria $10 \mathrm{~m}$. The effect of the TH lines on the TLP offset is practically quasi - static and the TLP may therefore operate with the AWB connected and with a watch to the offset in case of strong southerly current. From the tension results, TLP offset and clearance results, we found that there is no significant effect of the TH1 \& TH2 lines for the mooring lines system. Therefore, we can ignore the option to replace or repair those lines. However, the minor change of the vessel's mooring properties is needed 
to improve line tension capacity. The maximum line tension occurred in line D4 for damaged condition in case of strong northerly environmental forces.

\subsection{Reliability analysis Results}

In this study, we performed 50 Monte Carlo simulation to assess probability of failure from line D4 as representation from the recommended design. The wave height variable acted as load parameter while Minimum Breaking Load (MBL) of the line acted as resistance parameter with no safety factor applied (safety factor $=1$ ).

50 random northerly waves variable were developed using Kolmogorov - Smirnov $(\mathrm{K}-\mathrm{S})$ test [5]. The $\mathrm{K}-\mathrm{S}$ test compares the observed cumulative frequency and the CDF of an assumed theoretical distribution. The analysis conducted using ORCAFLEX simulation for dynamic mooring analysis in damaged condition without TH1\&TH2 lines. The failure criteria meet simply when the load is greater than line D4 capacity $(\% \mathrm{MBS}>1)$.

From the observed data (see Fig.11), normal distribution is closest (see Table.3) compared to data with level of significance factor $15 \%$.

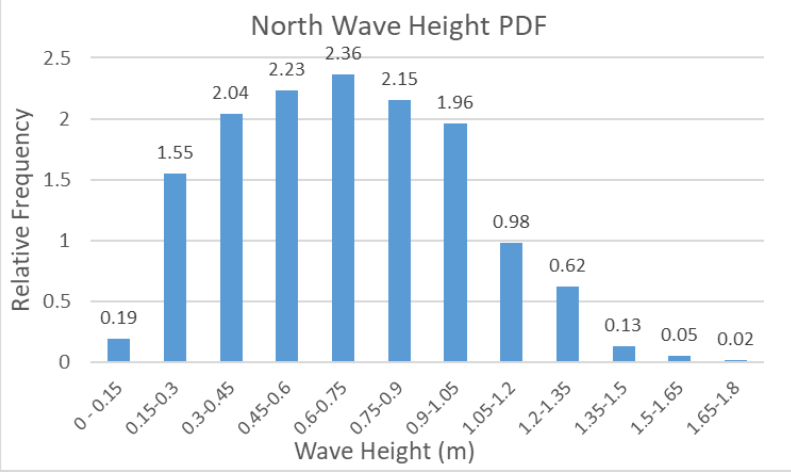

Fig. 11. North wave height observed data PDF
The $\mathrm{K}-\mathrm{S}$ test given the two parameters for normal distribution as mean $\left(\mu_{E}\right)=0.684 \mathrm{~m}$, and standard deviation $\left(\sigma_{E}\right)=0.313 \mathrm{~m}$. From this distribution parameter, we generated 50 random northerly wave height data (see Fig.13) to run on the simulation using MATLAB application.

Mooring analysis using ORCAFLEX simulation generated 50 simulations with 50 generated wave height data as load parameter. The results will be $50 \mathrm{MBS}(\%)$ data of line D4 from the recommended design.

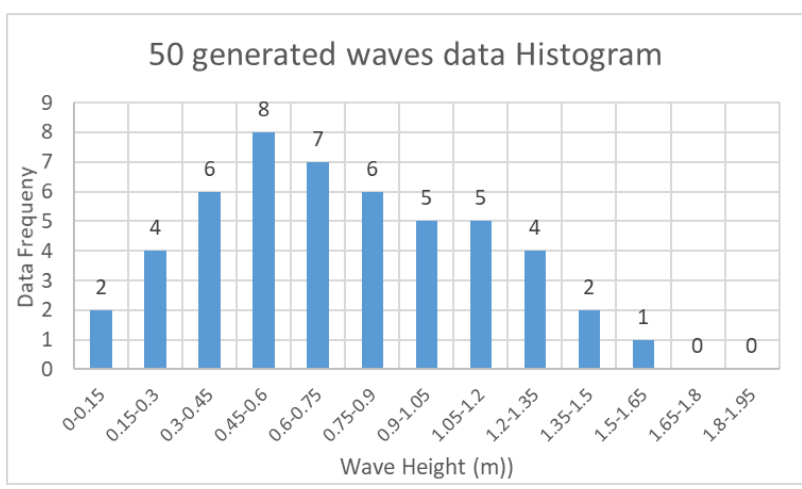

Fig. 12. Generated waves data for simulation

From the simulation results (see Table.4), it is found that none of the trials resulted in failure of the line, giving the corresponding probability of failure to be zero. This would happen when the number of simulation $(\mathrm{N})$ is relatively small (below 100 simulation). The maximum MBS result occurs in trial no. 39 with $48 \%$ MBS.

As there is no failure occur in the simulations, we still managed to calculate the probability of failure by analyse the PDF of MBS results (see Fig). The results data is closest (see table) to lognormal distribution based on the $\mathrm{K}-\mathrm{S}$ test with level of significance factor reach $15 \%$.

Table 3. 50-simulation results

The observed wave height data is a height $(\mathrm{H})$ and periode $(\mathrm{T})$ data with relation as shown in this formula. $T=1.9308 H+2.9198$

Table 4. $\mathrm{K}-\mathrm{S}$ test result distribution

\begin{tabular}{|l|c|r|}
\hline \multirow{2}{*}{ Distribution } & \multicolumn{2}{|c|}{ Kolmogorov Smirnov } \\
\cline { 2 - 3 } & $\mathbf{D}_{\mathbf{N}}$ & \multicolumn{1}{|c|}{ Rank } \\
\hline Normal & 0.1137 & 1 \\
\hline Rayleigh & 0.11524 & 2 \\
\hline Gumbel Max & 0.14362 & 3 \\
\hline Lognormal & 0.16258 & 4 \\
\hline
\end{tabular}

\begin{tabular}{|c|c|c|c|c|c|c|c|c|c|c|c|}
\hline & \multicolumn{6}{|c|}{ Steady State } & \multicolumn{3}{|c|}{ Steady State } \\
\hline No & $\mathbf{H}(\mathbf{m})$ & $\mathbf{T}(\mathrm{s})$ & $\begin{array}{l}\mathrm{D} 4 \\
\text { Tension } \\
(\mathrm{kN})\end{array}$ & $\begin{array}{l}\text { D4 } \\
\text { Tension } \\
(\mathrm{t}) \\
\end{array}$ & $\begin{array}{l}\text { D4 } \\
\text { \%MBS }\end{array}$ & No & $\mathbf{H}(\mathbf{m})$ & $\mathbf{T}(\mathrm{s})$ & $\begin{array}{l}\mathrm{D} 4 \\
\text { Tension } \\
(\mathrm{kN})\end{array}$ & $\begin{array}{l}\text { D4 } \\
\text { Tension } \\
(\mathrm{t}) \\
\end{array}$ & $\begin{array}{l}\text { D4 } \\
\% \mathrm{MBS}\end{array}$ \\
\hline 1 & 0.987 & 4.825 & 648.8 & 66.1 & $38 \%$ & 26 & 1.073 & 4.992 & 659.8 & 67.3 & $39 \%$ \\
\hline 2 & 0.694 & 4.259 & 626.9 & 63.9 & $37 \%$ & 27 & 0.585 & 4.050 & 619.8 & 63.2 & $36 \%$ \\
\hline 3 & 1.107 & 5.056 & 664.5 & 67.7 & $39 \%$ & 28 & 0.223 & 3.350 & 608.1 & 62.0 & $36 \%$ \\
\hline 4 & 0.202 & 3.310 & 608.3 & 62.0 & $36 \%$ & 29 & 0.409 & 3.709 & 612.4 & 62.4 & $36 \%$ \\
\hline 5 & 0.759 & 4.386 & 630.5 & 64.3 & $37 \%$ & 30 & 0.396 & 3.683 & 612.2 & 62.4 & $36 \%$ \\
\hline 6 & 0.297 & 3.494 & 610.3 & 62.2 & $36 \%$ & 31 & 1.408 & 5.638 & 728.3 & 74.2 & $43 \%$ \\
\hline 7 & 0.878 & 4.614 & 638.5 & 65.1 & $37 \%$ & 32 & 0.868 & 4.596 & 637.8 & 65.0 & $37 \%$ \\
\hline 8 & 1.092 & 5.029 & 662.4 & 67.5 & $39 \%$ & 33 & 0.587 & 4.053 & 616.9 & 62.9 & $36 \%$ \\
\hline 9 & 1.004 & 4.859 & 650.8 & 66.3 & $38 \%$ & 34 & 0.361 & 3.617 & 611.7 & 62.4 & $36 \%$ \\
\hline 10 & 1.380 & 5.584 & 720.7 & 73.5 & $42 \%$ & 35 & 0.612 & 4.100 & 621.6 & 63.4 & $36 \%$ \\
\hline 11 & 0.897 & 4.652 & 640.0 & 65.2 & $37 \%$ & 36 & 0.791 & 4.447 & 632.4 & 64.5 & $37 \%$ \\
\hline 12 & 0.687 & 4.246 & 626.5 & 63.9 & $37 \%$ & 37 & 1.460 & 5.739 & 742.9 & 75.7 & $44 \%$ \\
\hline 13 & 0.789 & 4.442 & 632.3 & 64.5 & $37 \%$ & 38 & 0.402 & 3.695 & 612.3 & 62.4 & $36 \%$ \\
\hline 14 & 0.513 & 3.910 & 614.8 & 62.7 & $36 \%$ & 39 & 1.613 & 6.034 & 817.8 & 83.4 & $48 \%$ \\
\hline 15 & 0.168 & 3.243 & 608.8 & 62.1 & $36 \%$ & 40 & 0.680 & 4.234 & 626.1 & 63.8 & $37 \%$ \\
\hline 16 & 0.963 & 4.780 & 646.2 & 65.9 & $38 \%$ & 41 & 0.059 & 3.033 & 604.7 & 61.6 & $35 \%$ \\
\hline 17 & 0.525 & 3.934 & 615.5 & 62.7 & $36 \%$ & 42 & 0.406 & 3.704 & 612.3 & 62.4 & $36 \%$ \\
\hline 18 & 0.581 & 4.041 & 619.5 & 63.1 & $36 \%$ & 43 & 0.553 & 3.987 & 617.4 & 62.9 & $36 \%$ \\
\hline 19 & 0.737 & 4.342 & 629.3 & 64.2 & $37 \%$ & 44 & 0.901 & 4.660 & 640.4 & 65.3 & $38 \%$ \\
\hline 20 & 1.478 & 5.773 & 784.5 & 80.0 & $46 \%$ & 45 & 0.633 & 4.142 & 623.1 & 63.5 & $37 \%$ \\
\hline 21 & 1.401 & 5.626 & 726.6 & 74.1 & $43 \%$ & 46 & 0.716 & 4.302 & 628.2 & 64.0 & $37 \%$ \\
\hline 22 & 0.272 & 3.444 & 609.2 & 62.1 & $36 \%$ & 47 & 0.678 & 4.230 & 626.0 & 63.8 & $37 \%$ \\
\hline 23 & 0.536 & 3.954 & 616.2 & 62.8 & $36 \%$ & 48 & 0.384 & 3.661 & 612.0 & 62.4 & $36 \%$ \\
\hline 24 & 0.993 & 4.837 & 649.5 & 66.2 & $38 \%$ & 49 & 1.051 & 4.949 & 656.8 & 67.0 & $38 \%$ \\
\hline 25 & 0.036 & 2.989 & 595.7 & 60.7 & $35 \%$ & 50 & 0.570 & 4.020 & 618.7 & 63.1 & $36 \%$ \\
\hline
\end{tabular}




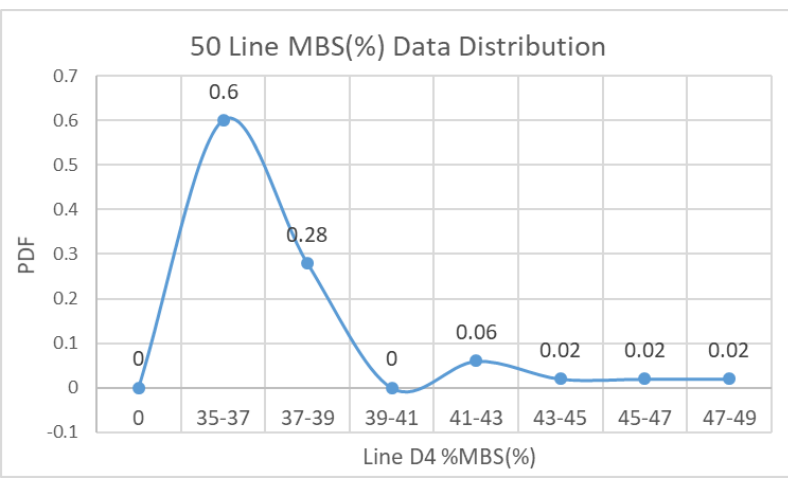

Fig. 13. Line MBS (\%) PDF

Lognormal distribution can be used to theoretically represent line D4 tension MBS data with parameter:

$$
\begin{array}{ll}
\text { - Mean } & \lambda_{M B S}=-0.98095 \\
\text { - Standar Deviation } & \xi_{M B S}=0.06684
\end{array}
$$

Table 5. K-S Test on MBS results

\begin{tabular}{|c|l|c|c|}
\hline \multirow{2}{*}{$\#$} & \multirow{2}{*}{ Distribution } & \multicolumn{2}{|c|}{$\begin{array}{c}\text { Kolmogorov } \\
\text { Smirnov }\end{array}$} \\
\cline { 3 - 4 } & & Statistic & Rank \\
\hline 1 & Lognormal & 0.21668 & 1 \\
\hline 2 & Normal & 0.22981 & 2 \\
\hline 4 & Weibull & 0.25255 & 3 \\
\hline 3 & Rayleigh & 0.49198 & 4 \\
\hline
\end{tabular}

From the above PDF, probability of failure $\left(\mathrm{P}_{\mathrm{f}}\right)$ of D4 as representative from the recommended mooring design can be calculated using the curve area where $1 \leq$ $\% M B S<\infty$. The area will be calculated using following formulae.

$$
\begin{gathered}
P(a<X \leq b)= \\
\sqrt{2 \pi} \int_{\left(\frac{\ln a-\lambda_{x}}{\xi_{x}}\right)}^{\left(\frac{\ln b-\lambda_{x}}{\xi_{x}}\right)} \exp \left[-\frac{1}{2} s^{2}\right] d s \\
=\Phi\left(\frac{\ln b-\lambda_{x}}{\xi_{x}}\right)-\Phi\left(\frac{\ln a-\lambda_{x}}{\xi_{x}}\right) \\
P(\text { success })=p_{s}=1-p_{f}
\end{gathered}
$$

Then we calculate the probability of failure on line D4 as shown in calculation below:

$$
\begin{gathered}
p_{f}=P(\% M B S \geq 1) \\
p_{f}=1-\left[\Phi\left(\frac{\ln 1-\lambda_{M B S}}{\xi_{M B S}}\right)-\Phi\left(\frac{\ln (-\infty)-\lambda_{M B S}}{\xi_{M B S}}\right)\right] \\
p_{f}=1-\left[\Phi\left(\frac{\ln 1-\lambda_{M B S}}{\xi_{M B S}}\right)-\Phi(-\infty)\right] \\
p_{f}=1-\left[\Phi\left(\frac{\ln 1-(-0.98095)}{0.06684}\right)-0\right] \\
p_{f}=1-\Phi(14.676)
\end{gathered}
$$

Using the equation (3), the reliability index is calculated:

$$
\begin{gathered}
\beta=\Phi^{-1}(\Phi(14.676)) \\
\boldsymbol{\beta}=\mathbf{1 4 . 6 7 6}
\end{gathered}
$$

The reliability index shows a very large value in offshore platforms reliability criteria [10] with very small probability of failure (below $10^{-7}$ ) on line D4 for damaged condition without TH1 \& TH2 lines.

\section{Conclusions}

To verify the mooring performances of an Accommodation Working Barge on Tension Leg Platform in Makassar Strait, this study has found that.

1) For the mooring configuration, all safety factors are verified with and without $\mathrm{TH}$ lines with recommendation to change the AWB mooring lines connected to the TLP with new IWRC $54 \mathrm{~mm}$ wires with MBL 174 tonnes from EEIPS $38 \mathrm{~mm}$ wires with MBL 90 tonnes. This change aimed to increase break capacity when the storm 100YRP occurs. It is advised to set the vessel wire loose (about $2 \mathrm{~m}$ ) when the storm occurs.

2) In the $100 \mathrm{YRP}$ storm conditions, the line tension limit, TLP offset, and clearance between two vessels satisfied all the API criteria.

3) The maximum tension limit occurs in line D4 (87.9 tonnes / 50.5\%MBS) for strong northerly environmental forces during 1-line failure condition. The maximum TLP offset is $27.89 \mathrm{~m}$ in case of strong southerly current, and the minimum clearance meet API criteria $(>10 \mathrm{~m})$ which is $15.7 \mathrm{~m}$ when easterly environmental forces occur.

4) Based on the mooring analysis, the effect of the TH lines on the system performances is practically nonsignificant. Therefore, the recommended design should proceed without TH1\&TH2 lines.

5) This study assesses reliability index of the recommended design using Monte Carlo simulation. The system has very high reliability index (14.68) with probability of failure below $10^{-7}$.

This work is supported by PT.ZEE Engineering Indonesia with the use of ORCAFLEX (version 10.1) program from Orcina.

\section{References}

1. S. K. Chakrabarti, Hydrodynamics of Offshore Structures, Plainfield: Computational 2 (1987)

2. O. M. Faltinsen, Sea Loads on Ships and Offshore Structures (1990)

3. American Petroleum Institute, API RP 2SK: Design and Analysis of Station keeping Systems for Floating Structures 3 (2005)

4. American Petroleum Institute, Recommended Practice for Planning, Designing and Constructing Fixed Offshore Platform - Load Resistance and Factor Design, API RP-2A LRFD 21 (1993)

5. A. Haldar, S. Mahadevan, Probability, Reliability, and Statistical Methods in Engineering, John Wiley \& Sons. Inc (2000)

6. Orcina, ORCAFLEX User Guide (2017)

7. Franklin Offshore International, Mooring Analysis Tirta Rajawali at West Seno TLP (2017) 
8. Unocal, SEA Engineering FPU Time Domain Global Performance \& Mooring Analysis Report: Appendix B. Metocean Criteria per ITB Documentation (2003)

9. Balmoral Marine, Balmoral Marine Equipment Handbook (2004)

10. Det Norske Veritas AS, Joint Industry Project Guideline for Offshore Structural Reliability Analysis: Application to Jacket Platforms (1996) 